\title{
Is There an Integrated Society in Urban Neighbourhoods of Klang Valley in Malaysia?
}

\author{
Melasutra Md Dali \\ Urban Studies \& Planning Programme, Faculty of Arts and Social Sciences, \\ University of Malaya, 50603, Kuala Lumpur, Malaysia \\ Tel: 60-3-7967-5698 E-mail: melasutr@um.edu.my \\ Nikmatul Adha Nordin \\ Urban Studies \& Planning Programme, Faculty of Arts and Social Sciences, \\ University of Malaya, 50603, Kuala Lumpur, Malaysia \\ Tel: 60-3-7967-5702 E-mail: nikmatul@um.edu.my
}

The research is financed by CEDER (CENTER OF ECONOMIC DEVELOPMENT AND ETHNIC RELATION, University Malaya). No. 211.23131.4211486

\begin{abstract}
One remarkable point about Malaysia is that it is a multi-ethnic country with Malays being the most dominant race, followed closely by the Chinese and the Indians which can be regarded as the minority group. This paper attempts to address the issues of social integration among these multi-ethnic groups in neighbourhoods of Klang Valley. Social integration can be best understood by the ability of a society that is composed by people of different classes, ethnicity and educational background to resolve conflicts that may occur between them. The levels of integration can be measured by levels of tolerance and interaction among the individuals regardless of their differences that may come in many forms: skin colours, languages, beliefs, cultures, values, class and so on. Thus, the question lies in whether it is possible to have an integrated society when the differences exist. Using the quantitative and qualitative approach, the research examines the way people from different ethnicity perceive their neighbourhoods. It also focuses on the levels of interactions among the multi-ethnic groups and seeks the underlying issues that may prohibit or hinder towards social integration.
\end{abstract}

Keywords: Social Integration, Neighborhood Development, Multi-racial Society

\section{Introduction}

When Malaysia (formerly known as Malaya) gained independence from the British in 1957, the nation was underpinned by the colonial policy of "divide and rule", whereby the native Malay community had been left to remain in its traditional occupation such as paddy farming, whilst the Chinese immigrants were brought to town to work in the tin mines and the Indian immigrants were brought to work at rubber plantations. The British through its decentralization programme has extended the opportunities to the Malays to get employed in administration sector, whilst the non-Malays were banned from this sector. On top of that, the British adopted a laissez-faire attitude towards the non-Malays as they felt that those immigrants from China and India came to Malaya out of their own will and thus making the British as the colonial master shall not bear any responsibility for them. Those measures were seen as pro-Malay policies, employed by the British to appease the Malays who were at that time were showing a rise in nationalism movement (Cheah, 2009).

On top of the ethnic division of labour, the segregation between the three major ethnic groups in Malaysia was made deeper by the British education policy that allows various types of vernacular schools to operate. During British colonization, there were four types of schools: the English-medium, Malay-medium, Chinese-medium and Tamil-medium schools. Each used different mediums of instruction and provided a different syllabus. Except for English-medium school, other vernacular schools catered to only a particular ethnic group, were run by either missionaries, rubber and coffee plantation owners, and local residents' association. Cheah (2009) feels that the attitudes and policies of the British during its colonization period had over time gradually sown the seeds of ethnic consciousness within each of the three major races in Malaya.

The inter-ethnic relationship in Malaysia somehow improved during the Emergency period due to the common aim and understanding for the need of cooperation between races in order to achieve independence (Sri Rahayu et. al., 2009). A political alliance known as Perikatan which consists of the United Malay National Organization (UMNO) represented by the Malay ethnic group, the Malaysia Chinese Association (MCA) representing the Chinese and the Malaysia Indian Congress (MIC) representing the Indians, were formed to free Malaya from colonization.

Today, in modern Malaysia, national unity continues to be the main objective of socio-economic development. 
The national philosophy of development is to create a united nation based on fairness and prosperity and removing socioeconomic differences among ethnic groups. Social integration within neighbourhoods, nation, regions as well as global may has continued to receive priority. It is deemed that the rapid economic growth, increased population movements and advanced technologies, including the information explosion, will bring changes in not only economic but also social relationships.

Within the context social integration, the Malaysian Government has strongly advocated that economic development must involve and accrue to all citizens. National development must be balanced by a strong and real emphasis on equitable distribution of development benefits. This philosophy of growth with equity is embodied in all national development policies- the National Economic Policy formulated in 1970 and National Development Policy (2000). The NEP had two prongs, namely "poverty eradication regardless of race" and "restructuring society to eliminate the identification of race with economic function". The NEP was supposed to create the conditions for national unity by reducing interethnic resentment due to socioeconomic disparities. However, the NEP policies have often been criticized as being pro-Malay. The NEP has since been replaced by the National Development Policy associated with the Second Outline Perspective Plan for 1991-2000, and then by the National Vision Policy linked to the Third Outline Perspective Plan for 2001-2010. Although the new policies have put far greater emphasis on achieving rapid growth, industrialization and structural change, there is the widespread perception that public policy is still dominated by the NEP's interethnic economic policies (Jomo, K.S., 2004)

While some of the socioeconomic targets of the NEP and NDP have been largely achieved, however, there is little evidence that shows such achievement has led to improve social unity and integration among people from different ethnic backgrounds. Jomo, K.S (2004) feels that the these ethnic affirmative action policies as implemented and enforced in Malaysia have raised more resentments as these policies were seen as discouraging fair competitions between ethnics and between people of different socioeconomic status.

In Malaysia, social and economic development programmes were implemented to integrate the population, especially the indigenous segment, into the modern economy as quickly as possible and redistribute the wealth of the nation. The focus of the development agenda is on growth, employment and social stability. Programmes to improve the quality of life of the population through the provision of essential social services such as primary health care, education and housing were implemented. This included:

- the construction of low-cost housing for the low-income group and resettlement of squatters

- the construction of hospitals and clinics as well as upgrading of the existing facilities

- the construction and upgrading of schools, polytechnics, universities and colleges

The Government had to put in place the right mix of economic and social policies to ensure that economic and social goals are simultaneously met. Through the implementation of various economic and social policies and programmes, the Government played an active role in delivering essential social services directly to the people. There has been tremendous improvement in the quality of life of the population as seen in the quality of life indicators from the Second Malaysia Plan to the Seventh Malaysia Plan (Note 2). Improvements in the quality of life of the population have been a result of social policies and economic development.

Similar to other countries around the world, Malaysia is experiencing an increasing rate of urbanization. From $1995-2000$ it grew at $4.8 \%$ p.a. reaching a level of $62 \%$ in 2000 (Dept of Statistics, 2000). The impact on the process of urbanization and urban growth has been most tangible in terms of employment opportunities, income level and the provision of basic urban services and social amenities. While major improvements in infrastructure and facilities are undertaken, rapid urbanization also brings imbalances and disparities between inter and intra metropolitan areas. Rural-urban migration and the influx of foreign workers contributed to the increase in population density in metropolitan areas. This has led to continued inadequacy of physical (especially housing and sanitation), social and health infrastructure which has an effect on the quality of life of the urban population.

Klang Valley is an area in Malaysia comprising Kuala Lumpur and its suburbs and adjoining cities in the state of Selangor. It is geographically delineated by Titiwangsa Mountains to the north and east and the Strait of Malacca to the west. The conurbation had an estimated total population 6.5 million in 2006 , and is the heartland of Malaysia's industry and commerce. The Klang Valley region consists of the Federal Territory of Kuala Lumpur and the Selangor districts of Gombak, Petaling, Hulu Langat and Klang and several local authorities including three important councils namely Kuala Lumpur City Hall, Shah Alam City Council and Petaling Jaya City Councils (Figure 1). This complex conurbation developed historically through the progressive development of satellite towns from Kuala Lumpur, especially after World War 11. Despite its small area of about 2,843 square kilometers, which is approximately $1.25 \%$ of the size of Malaysia, the region's population represents for 17.4 percent of the national population. For an urban area, it is a heterogenous place. It is a cultural melting pot where it serves as a meeting place of people from different ethnic, cultural, educational and social background. The heterogeneity of the city however, has invited many differing opinions with regards to the level of integration among the urban dwellers. The existence of many diverse factors such as ethnicity, religion, culture, social and economic status has been seen as major challenges that may cause social integration to be an elusive reality. 
In this context, the researchers have taken the initiative to study the spatial dimensions of social integration by comparing and investigating specific neighbourhoods in Klang Valley region, and more precisely, by examining the relative spatial/physical effectiveness for realizing integration in society.

\section{Understanding Integration}

Integration is defined in so many ways. The Copenhagen Declaration on Social Development defines integration as:

the process of fostering societies that are stable, safe and just and that are based on the promotion and protection of all human rights, as well as on non-discrimination, tolerance, respect for diversity, equality of opportunity, solidarity, security and participation of all people, including disadvantaged and vulnerable groups and persons.

(United Nations, Commitment 4, para 1)

To promote integration, the UN Commission for Social Development has emphasized the importance of adjusting social institution to allow greater accommodation of the needs of people from diverse backgrounds.

Moreover, various types of integration also exist, and exploring them is worthwhile. One type might be called amalgamation - the literal blending of races through interracial marriage, resulting in a new multiracial hybrid.

Another brand of integration is less focused on inculcating interracial attachments and more concerned with the strategic placement of certain ethnic groups in influential, power-shaping forums. This approach fosters policies that assure the presence of racial minorities in a wide variety of institutional settings, including universities (in both student and faculty populations), workplaces, juries, governmental commissions, boards of trustees and directors, slates for honorary degrees and other awards, and so on. This might be called diversity integration, and it is currently the most widely practiced and consequential form of racial integration.

Integration is sometimes said to be synonym to desegregation. Desegregation, as the structure of the word suggests, aims principally to undo segregation. Thus another term -integration- is needed to describe policies that are aimed, for instance, at creating or sustaining inter-racial interaction in an institution.

Social inclusion is a term that has the same connotation as social integration. According to the Australian government website, a socially inclusive society refers to a condition where everyone feels valued and is given the opportunity to participate fully in the life of a society by having equal access to the resources, opportunities and capability to learn, work engage in the community. In Canada, the Laidlaw Foundation (2002) has proposed a framework of social inclusion. According to the Laidlaw Foundation, inclusion depends on the satisfaction one has on the following elements:

i. $\quad$ spatial - which includes elements such as public spaces, private spaces, physical location, geographic proximity/distance, economic proximity/distance;

ii. relational - which includes elements such as social proximity/distance, emotional connectedness, recognition, solidarity

iii. functional/development - which includes elements such as capabilities, developmental capabilities, assets/liabilities, talents / potentials, human capital; and

iv. participation / empowerment strategy - which includes elements such as power.

In recent years, there has been a growing interest among scholars in studying the social cohesiveness of people in urban area. It has been observed that people in urban areas are becoming more disconnected to one another. As Berry et. al. (1993) put it, people can live next to one another without being neighbours. It is observed that people nowadays are leading more individualized and impersonalized lifestyles and this has caused them to be disassociated with their neighbours.

One of the main characteristics of urban people as observed by Fischer (1984) in Pallen (1992) is that urban dwellers know fewer of their neighbours. Palen raises one important question on what social conditions that make people who are living near to one another as real neighbours? Fischer as quoted by Palen feels that the following are the three main conditions that turn "just neighbours" to "real neighbours":

i. functional interdependence - this involves mutual help that generates social cooperation such as neighbourhood watch and community policing;

ii. preexistence of other relationships and bond such as sharing the same ethnicity;

iii. sharing the same limited alternatives - for example the elderly and mothers with small children with reduced mobility may form close relationship with those nearby.

Accommodation refers to the act of internalizing the differences whereby the collective characteristics of certain groups become accepted as distinctions within social positions and membership groups (Ellie, 2009). Ellie (2009) elaborates that mutual accommodation should not only occur at an everyday level, but it must involve mutual recognition of values and culture and allows some structural changes to occur in order to ensure structural equality for ethnic minorities. In a multi-ethnic country such as Malaysia, this may be done by provision of opportunities 
and facilities to the non-Malays in pursuing their custom and religion beliefs, as well as in obtaining good education.

Based on the definitions of integration and other related concepts to it, it can be seen that to make people connected to one another, it must involve effort to reduce the gap between one group to another. While it is acknowledged that reducing economic disparities is an important strategy, however it is equally important to study the social similarities and values that exist among the different groups and seek the potential on how to these similarities can be enhanced in order to create a harmonious community regardless of the ethnic differences.

\section{Theoretical Framework}

When discussing the modes of integration, social integration, besides economic aspect, is emphasized because this is viewed as an important step into real integration, or as what the Malaysian government put it - the national integration. The principal analytic framework for our study of social integration is based on three components of social elements: participation, interaction and accommodation (Figure 2). Originally, this framework is inspired from a well established and developing body of literature (Bobo, L and Zubriansky, C. 1996; Brower, S. 1996) that put forward the importance of participation and interaction as the prerequisites of integration. The authors argue that participation (understood as by being present in public space and public forums) is a prerequisite for interaction and that interaction (which implies communication and the exchange of ideas) is a prerequisite for integration, which in its social aspect has been interpreted as the sharing of common values and norms or principles of behaviour. However, the latter interpretation of social integration seems too be limited in contemporary multi-cultural and multi-ethnic societies such as Malaysia. Thus, it is felt that in multi-ethnic population, another important criteria is accommodation or understanding which stress that members of the society should be considerate of people who belong to the 'other group' and this can be achieved by simply acknowledging and respecting the rights and obligations of the 'others'.

Based on the above explanation, the overall aim of the research is to discover the extent to which and how participation and interaction could contribute to promoting social integration and combating social exclusion. This study embarks on focussing on the social processes which centred on the everyday interactions and encounters between neighbours, and how the people who have been living with neighbours whom mainly of the same skin colours perceive the possibility of interactions that may occur if they were made to live with neighbours of different colours.

\section{Methodology}

This paper offers empirical data on a recent study of three neighbourhoods in Klang Valley of an area of older urban village which is predominated by the Malays, an inner-city area of high-rise flats predominated by the Chinese and a planned housing estate which is dominated by Indian communities. 900 questionnaires were originally used in this study, but the final counts saw a total of 891 respondents. Below is the ethnic breakdown of the respondents (Refer Table 3.1).

The questions aimed to understand on how the residents experience their neighbourhoods, whether the residents know their neighbours, trust their neighbours, whether they help one another and whether their neighbours matters to them. The study also tries to explore the differing attitudes that the residents may have towards neighbours of different races. In this context, the researchers have taken the initiative to explore on how the Malays, the Chinese and the Indians, having been residing in housing area that predominated by their own respective races, feel about socializing and mixing with people of different races, for example, would they help their neighbours in cases of emergencies if the neighbours had different skin colours. The study also highlighted on the respondents' perceptions on the importance of participating in neighbourhood activities and local organizations.

\section{Study Findings}

\subsection{Acquaintance with neighbours}

Knowledge of neighbours and mutual trust are prerequisites in ensuring social unity among the neighbours. Neighborhood relationship or desire for community can be measured by taking into consideration the number of individuals that we know in our area we live, or the number of neighbours we remember their names. According to Warren (1986), knowing neighbours may refer to the existence of social ties and interaction of occupants in housing area.

From the survey, it can be seen that in general, the respondents are aware of their neighbours and generally look out for each other. Table 4.1 shown that Malay respondents reflect a higher level of neighbouring awareness compare to the Chinese and Indians. Majority of Malay respondents $(84.5 \%)$ indicated that they recognize at least 10 people living in their neighbourhoods, even though they might not know them in person. The respondents were also asked on the number of neighbours they knew in person and again, the result shows that the Malays are more sociable as $71 \%$ of Malay respondents responded that they know more than 10 neighbours in person, followed by the Indians (51\%) and the Chinese (43\%). 
When referring to interactions among ethnics, many of them prefer the mixing ethnic housing environment as they believe that living with other races help them to understand the other races better. However not many prefer to stay side-by-side or become neighbours within one housing block, because of lack of understanding on socio-culture aspect between different races. It should be noted though, from the survey, it was found that the Indians were more open in this matter as $51 \%$ of Indian respondents disagree with the statement that they prefer to live next door with only Indians.

The findings also show that the Malay and Indian respondents are more sociable than the Chinese as they literally communicate with neighbours every day after work. 27.9 percent of the Chinese respondents stated that they only communicate with neighbours only at functions and not on regular basis. Most of the respondents surveyed stated that they usually interact with neighbours at their house compounds and some even go to their neighbours' homes for chit chatting.

\subsection{Neighbourliness activities}

Neighbourliness activities such as holding functions or kenduri (Note 3) could promote better interaction and unity among the neighbours. The survey did not only try to establish whether there have been special occasions organized by the respondents but it also attempted to investigate whether the invitations to the functions were extended to neighbours of different races. It was found that the Malays and Indians were more active in organizing functions as compared to the Chinese. When asked on whether the invitation to attend the functions were extended to neighbours of different race, most of them stated that they do or would invite neighbours from different race, and some of them stated that it depends on the purpose of the functions. This is understandable as some of the functions organized were associated with their religions and the invitations were only extended to those in the same belief and faith.

The following table summarizes the levels of neighbourly contacts of the residents surveyed based on their ethnic groups (Refer Table 4.2).

In general, it can be observed that the respondents from all races have high level of tolerance. They were asked if there were any activities done by their neighbours that made them feel disturbed or annoyed. It was found that almost half of the respondents from all races stated that there were occasions when they feel disturbed with their immediate neighbours' activities. A further investigation was made on the types of activities that made the respondents feel annoyed and disturbed. It was found that most respondents stated "loud noise from neighbours' house" as the main reason why they feel disturbed. This shows that the factor contributing to the annoyance feeling is an acceptable common factor and has nothing to do with racial or religious activities.

Exchanging food with neighbours have always been the norms for the Muslim Malays especially in the fasting month. The willingness to exchange food with neighbours indicates a higher level of interactions as most people do not accept food from just anybody. From the survey, it was found that while most of the respondents surveyed do exchange food with their neighbours occasionally, however, most of them only exchange food with neighbours of the same race. The Indians are quite open in this matter as compared to the Malay and Chinese respondents as more than half of the Indians surveyed responded that they are willing to exchange their food with neighbours from different race.

Neighbours are usually seen as sources of practical assistance in the situation whereby you are able to borrowing things and exchanging favours such as taking care of child, feeding a pet, holding door keys when the neighbours are away for vacations. These kinds of short, informal moments of care and assistance can be used to gauge the extent of neighbourliness. The mutual exchange of favours does, however, appear to be much prevalent within Chinese and Indian communities. However, when asked on their willingness to help in cases of emergencies, for example, if the neighbour was ill, majority of them agreed that they would offer their assistance regardless of their skin colours.

\subsection{Neighbourhood facilities as means of social integration}

Public space provides a venue for chance encounters, which serves to strengthen community bonds. Neighbourhood gathering places give 'heart' to the community and serve as a counter-pressure to community fragmentation which results when communication is privatised. Public spaces in the form of parks and civic centres also serve as symbols of civic pride and sense of place which promote the notion of community.

If public spaces are a pleasurable place for communation, they will be used, and its usefulness as promoters of sense of community will flourish. As agreed by Duany and Plater (1992) sense of place is created simply by paying attention to sense of space through proper design and placement of public space. The immediate surroundings, i.e. the building, street and block around one's residence, provides an opportunity and a concrete space in which identity can be asserted by appropriating and designing/using a space according to one's needs. In general, respondents from all races feel that the physical design of their neighbourhoods do not hinder them to express their religious and cultural rituals.

The respondents were also asked on their perceptions of sharing facilities with other races. The Malay and Indian respondents have more positive attitude on this matter and majority of them also strongly feel that the facilities 
provided able to promote better interactions with other races. When asked on whether the facilities provided were fairly managed for everyone, again, the Malays and Indians have more positive view as compared to the Chinese (Refer Table 4.3)

\subsection{Residents organization as means of integration}

The study also highlighted the organizational activities amongst residents as means of integration. The dimension of integration is measured through the residents' participation in resident association or organization, their involvement in decision-making processes, and the individual willingness to participate in public and political life (refer Table 5). It refers to the formal and informal ways in which the residents determine the use and appearance of the spaces in their neighbourhood. Equal rights to participate, and a transparent, open participatory process that involves all resident groups in the neighbourhood are prerequisite to ensuring that the specific interests of different ethnic groups can be articulated and co-ordinated. The structure and functionality of a neighbourhood contributes to the ability of groups to appropriate space (refer Table 4.4).

The findings of the survey showed that the involvement of respondents in resident organizations is rather minimal for all the three races. However when asked on whether they feel that their involvement help them to socialize with members of different race, majority of them agreed.

\section{Concluding Remarks}

This study shows that the interactions between ethnic groups in the three neighbourhoods can best be described a community that able to live within the locality with certain degree of tolerance. It supported the prevalence hypotheses that residents' relationship could best be described as living 'next to' each other as opposed to living 'with one another' which is a bit too ambitious. Strained relations and latent conflicts are common among people especially in a society like Malaysia that have been preceded by long social history and conflicts. One might argue that such situation might be results of negative experiences with other group, but the study shows that sometimes it was due to the lack of opportunities for contact and exchange with the one other. The prejudices are not so much the result of actual contacts, as they are the result of what residents see and observe in the public spaces in their neighbourhood. The residents react in part by retreating from certain parts of the neighbourhood or into closed ethnic groups, and in part by means of growing aggression aimed towards the 'others'.

Relations between ethnic groups cannot be planned and they cannot be predicted on the basis of the resident mix in a specific neighbourhood. However, it can be definitively stated that if more heterogeneity is allowed within neighbourhoods, the variety of lifestyles in the housing units increases, and the opportunities for intercultural interaction are also increased.

We believed the "melting-pot" or amalgamation phenomenon could have happened slightly, but we can be satisfied with the fact that our society is living in a 'salad bowl' environment whereby we are willing to accept each other differences and respect each other practices and that will makes our neighbourhood diversify yet remain cohesive.

\section{References}

Australian Government. (2010). Social Inclusion. Retrieved from http://www.socialinclusion.gov.au

Berry, J.M, Portney, K.E. and Thomson, K. (1993). The Rebirth of Urban Democracy. Washington: The Brookings Institution.

Bobo, L and Zubriansky, C. (1996). Attitudes on residential integration: perceived status differences, mere in-group preferences or racial prejudice? Social Forces 174 (2)

Brower, S. (1996). Good Neighbourhoods. Westport, CT: Praeger. BURNS, D. and TAYLOR, M. (1998) Mutual Aid and Self Help: Coping Strategies for Excluded Communities. Bristol: The Policy Press.

Cheah Boon Kheang. (2009). Race and Ethnic relations in Colonial Malaya during the 1920s and 1930s. In Multiethnic Malaysia: Past, Present and Future. Lim Teck Ghee, Alberto G. Gomes and Azly Rahman (eds) Petaling Jaya: SIRD and Kuala Lumpur: UCSI University.

City Hall of Kuala Lumpur. (2003). 'Kuala Lumpur Structure Plan 2020'. City Hall of Kuala Lumpur, Kuala Lumpur.

Cochrun, S. (1994). "Understanding and Enhancing Neighbourhoood Sense of Community." Journal of Planning Literature 9(1): 92-99.

Davidson, W. B. and P. R. Cotter. (1986). "The Measurement of Sense of Community within the Sphere of City." Journal of Applied Psychology 16: 608-619.

Duany and Plater. E. (1991). Towns and Town-making Principles. New York .Rizzoli.

Freeman, L. (2001). "The Effects of Sprawl on Neighbourhood Social Ties: An Exploratory Analysis." Journal of the American Planning Association 67(1): 69-77.

Forrest, R. (2000). Does neighbourhood still matter in a globalised world?. Occasional Paper Series No. 5. Centre for Comparative Public Management and Social Policy, City University of Hong Kong. 
Guest, A. M. and S. K. Wierzbicki. (1999). "Social Ties at the Neighbourhood Level. Two Decades of GSS Evidence." Urban Affairs Review 35(1): 92-111.

Gustavo, S. M. and O. Manor. (2001). "Ethnic Differences in Urban Neighbour Relations in Israel." Urban Studies 38(11): 1943-1952.

Jeannotte, M. Sharon. (2008). Promoting Social Integration: A Brief Examination of Concepts and Issues. Finland: Experts Group Meeting, July 8-10.

Jomo K.S. (2004). The New Economic Policy and Interethnic Relations in Malaysia. In Identities, Conflict and Cohesion (2000 - 2005), Paper 7 . United Nations Research Institute for Social Development.

Kleit, R. G. (2001). "Neighborhood Relations in Suburban Scattered-Site and Clustered Public Housing." Journal of Urban Affairs 23(3-4): 409-430.

Laidlaw Foundation. (2002). The Laidlaw Foundation's Perspective on Social Inclusion. Toronto: The Laidlaw Foundation.

Little, S. E. (2000). "Networks and Neighbourhoods: Household, Community and Sovereignty in the Global Economy." Urban Studies 37(10): 1813-1825.

Malaysia, Department Of Statistics. (2000). Preliminary Count Report: population and Housing Census of Malaysia, Kuala Lumpur.

Malaysia. (1995). Seventh Malaysia Plan 1995-2000. Kuala Lumpur: Economic Planning Unit, Prime Minister's Department, Malaysia.

Palen, J.J. (1992). The Urban World. New York: McGraw-Hill, Inc.

Schwab, W.A. (1982). Urban Sociology: A Human Ecological Perspective. California: Addison Wesley

Sim, L.L, Shi, M.Y \& Sun, S.S. (2003). Public housing and ethnic integration in Singapore. Habitat International 293 (15)

Skjaeveland, O., T. Garling, et al. (1996). "A Multidimensional Measure of Neighboring." American Journal of Community Psychology 24(3): 413-435.

Sri Rahayu, I., Haslinda, A., Zaid, A. (2009). The Socio-Psychological Dimension of Ethnic Relations in Malaysia. European Journal of Social Sciences. 12 (1), 76-82.

Vasta, Ellie. (2009). Accommodating diversity: Understanding Multiculturalism. Retrieved from http://www.confluence.org.uk

Warren, D. I. (1986). The Helping Roles of Neighbours: Some Empirical Patterns. Urban Neighbourhoods: Research and Policy. R. B. Taylor. New York, Praeger: 310-330.

Notes:

Note 1. Dewan Bandaraya Kuala Lumpur (City Hall of Kuala Lumpur or CHKL) is a municipal government established in accordance with Local Authorities Elections Ordinance, 1950, and Kuala Lumpur was granted municipal status in 1952. With the declaration of Kuala Lumpur as a city in 1972, Kuala Lumpur Municipality became known as City Hall

Note 2. The sequence of Malaysian Plans is a set of plan outlines for every five years that ensure balance and equitable growth of Malaysian development, starting with First Malaysian Plan in 1965. The Seventh Malaysian Plan covers developmental policies and strategies for the years 1995-2000.

Note 3. It refers to having a feast or gathering of relatives, friends and neighnbours for special events.

Table 3.1 Respondents' ethnic breakdown

\begin{tabular}{|c|c|c|c|c|c|c|c|}
\hline \multicolumn{8}{|c|}{ Neighbourhoods } \\
\hline \multirow[t]{3}{*}{ Respondents } & \multicolumn{2}{|c|}{ Kg. Melayu Subang } & \multicolumn{2}{|c|}{ Tmn. Sentosa } & \multicolumn{2}{|c|}{ Hang Tuah } & \multirow[b]{2}{*}{ Tota } \\
\hline & Num of & $\%$ & Num of & $\%$ & Num of & $\%$ & \\
\hline & Responden & & Responden & & Responden & & \\
\hline \multicolumn{8}{|l|}{ Race } \\
\hline Malay & 250 & 85.9 & 49 & 16.3 & 103 & 34.3 & 402 \\
\hline Chinese & 34 & 11.7 & 102 & 34 & 101 & 33.7 & 237 \\
\hline Indians & 7 & 2.4 & 149 & 49.7 & 96 & 32 & 252 \\
\hline Total & 291 & 100 & 300 & 100 & 300 & 100 & 891 \\
\hline
\end{tabular}

Source: Study survey 2008. 
Table 4.1 Neighbourly Contact

\begin{tabular}{l|c|c|c|c}
\hline Percentage of respondents who: & Malay & Chinese & Indian & $\mathrm{X}^{2}$ \\
\hline $\begin{array}{l}\text { Recognize at least 10 familiar faces in } \\
\text { the neighbourhood }\end{array}$ & 84.5 & 60.1 & 63.5 & 84.3 \\
\hline Know at least 10 neighbours in person & 71.0 & 45.3 & 51.2 & 84.3 \\
\hline $\begin{array}{l}\text { In general agree that living in } \\
\text { multi-racial communities helps to foster } \\
\begin{array}{l}\text { respect and understanding towards other } \\
\text { races }\end{array}\end{array}$ & 66.3 & 65.8 & 87.3 & 78.6 \\
\hline $\begin{array}{l}\text { In general agree that they prefer to live } \\
\text { next door with neighbours of same race }\end{array}$ & 77.6 & 71.7 & 48.0 & 100.1 \\
\hline Communicate every day with neighbours & 77.3 & 45.1 & 77.7 & 109.4 \\
\hline $\begin{array}{l}\text { Go to their neighbours' homes for chit } \\
\text { chatting }\end{array}$ & 65.9 & 59.7 & 65.2 & 43.2 \\
\hline
\end{tabular}

Source: Study survey 2008

Table 4.2 Neighbourliness activities

\begin{tabular}{l|c|c|c|c}
\hline Percentage of respondents who: & Malay & Chinese & Indian & $\mathrm{X}^{2}$ \\
\hline $\begin{array}{l}\text { Have no problems in inviting neighbour } \\
\text { of different race to attend their functions }\end{array}$ & 54.3 & 50.0 & 60.6 & 13.9 \\
\hline $\begin{array}{l}\text { Have experienced being invited by their } \\
\text { neighbours of different race to attend } \\
\text { functions }\end{array}$ & 61.6 & 71.3 & 87.9 & 51.9 \\
\hline $\begin{array}{l}\text { Have no problems in exchanging food } \\
\text { with neighbours of different race }\end{array}$ & 33.5 & 35.1 & 62.5 & 58.0 \\
\hline $\begin{array}{l}\text { In general agree that they do not mind } \\
\text { lending their things to neighbours }\end{array}$ & 87.25 & 90.7 & 94.8 & 39.6 \\
\hline $\begin{array}{l}\text { In general agree that they do not mind } \\
\text { borrowing things from their neighbours }\end{array}$ & 79.8 & 88.5 & 91.3 & 43.4 \\
\hline $\begin{array}{l}\text { Willing to help out in cases of } \\
\text { emergencies, even to neighbours of } \\
\text { different race }\end{array}$ & 85.6 & 72.2 & 94.4 & 45.0 \\
\hline $\begin{array}{l}\text { At times feel annoyed with their } \\
\text { neighbours activities }\end{array}$ & 38.9 & 45.7 & 44.8 & 39.2 \\
\hline
\end{tabular}

Source: Study survey 2008

Table 4.3 Respondents' views on neighbourhood design and facilities provision

\begin{tabular}{l|c|c|c|c}
\hline Percentage of respondents who: & Malay & Chinese & Indian & $\mathrm{X}^{2}$ \\
\hline $\begin{array}{l}\text { Feel that the design of their housing area } \\
\text { fulfil their religiouss and cultural needs }\end{array}$ & 94.7 & 89.4 & 98.8 & 20.72 \\
\hline $\begin{array}{l}\text { Strongly agree that they have no } \\
\text { problems in sharing facilities with } \\
\text { neighbours of different race }\end{array}$ & 72.2 & 64.8 & 87.3 & 56.3 \\
\hline $\begin{array}{l}\text { Strongly agree that the community } \\
\text { facilities provided able to enhance social } \\
\text { integration }\end{array}$ & 84.2 & 67.1 & 88.2 & 91.9 \\
\hline $\begin{array}{l}\text { Strongly agree that the community } \\
\text { facilities provided in their neighbourhood } \\
\text { are fairly managed for everyone }\end{array}$ & 83.5 & 66.2 & 84.1 & 48.1 \\
\hline
\end{tabular}

Source: Study survey 2008 
Table 4.4 Respondents' Involvement in Residents Organization

\begin{tabular}{l|l|l|l|l}
\hline Percentage of respondents who: & Malay & Chinese & Indian & $\mathrm{X}^{2}$ \\
\hline $\begin{array}{l}\text { Have memberships in community club or } \\
\text { organizations }\end{array}$ & 18.2 & 8.4 & 6.0 & 25.7 \\
\hline $\begin{array}{l}\text { Feel that their involvement in the } \\
\text { organization help them to interact with } \\
\text { people of different race }\end{array}$ & 87.2 & 85.0 & 76.9 & 43.2 \\
\hline
\end{tabular}

Source: Study survey 2008

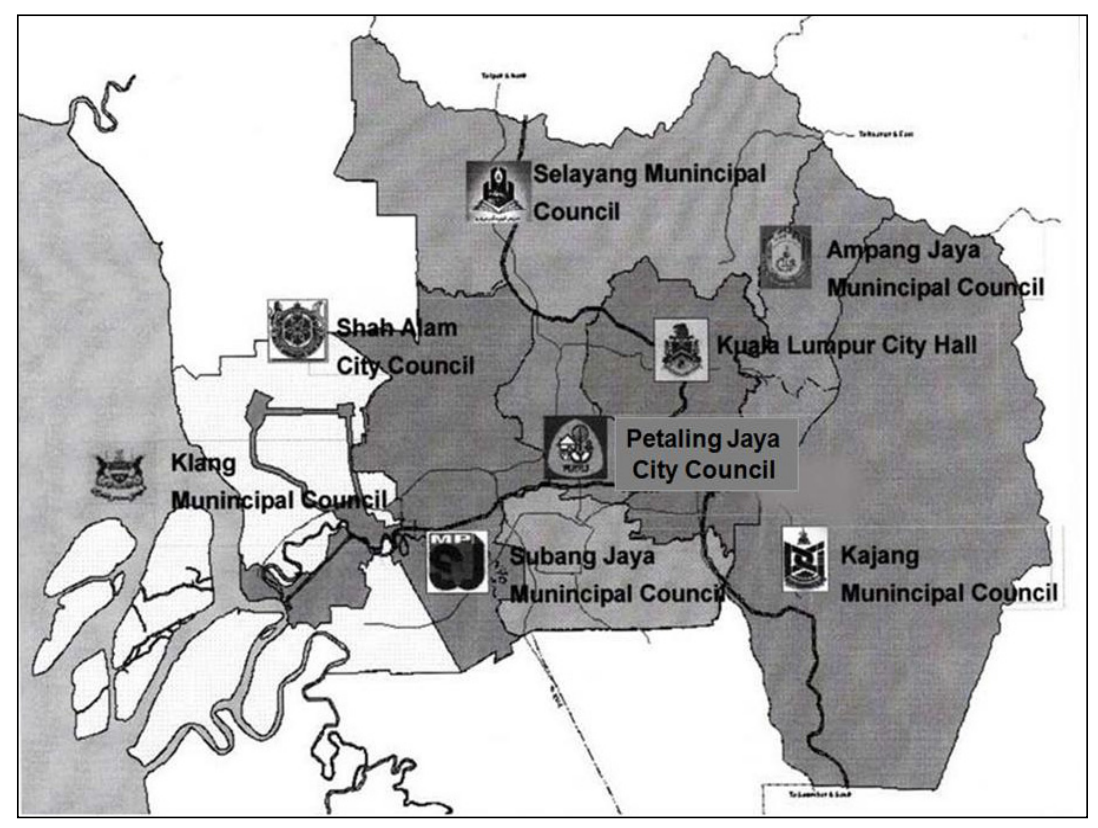

Figure 1. Map of Klang Valley and its Local Authorities

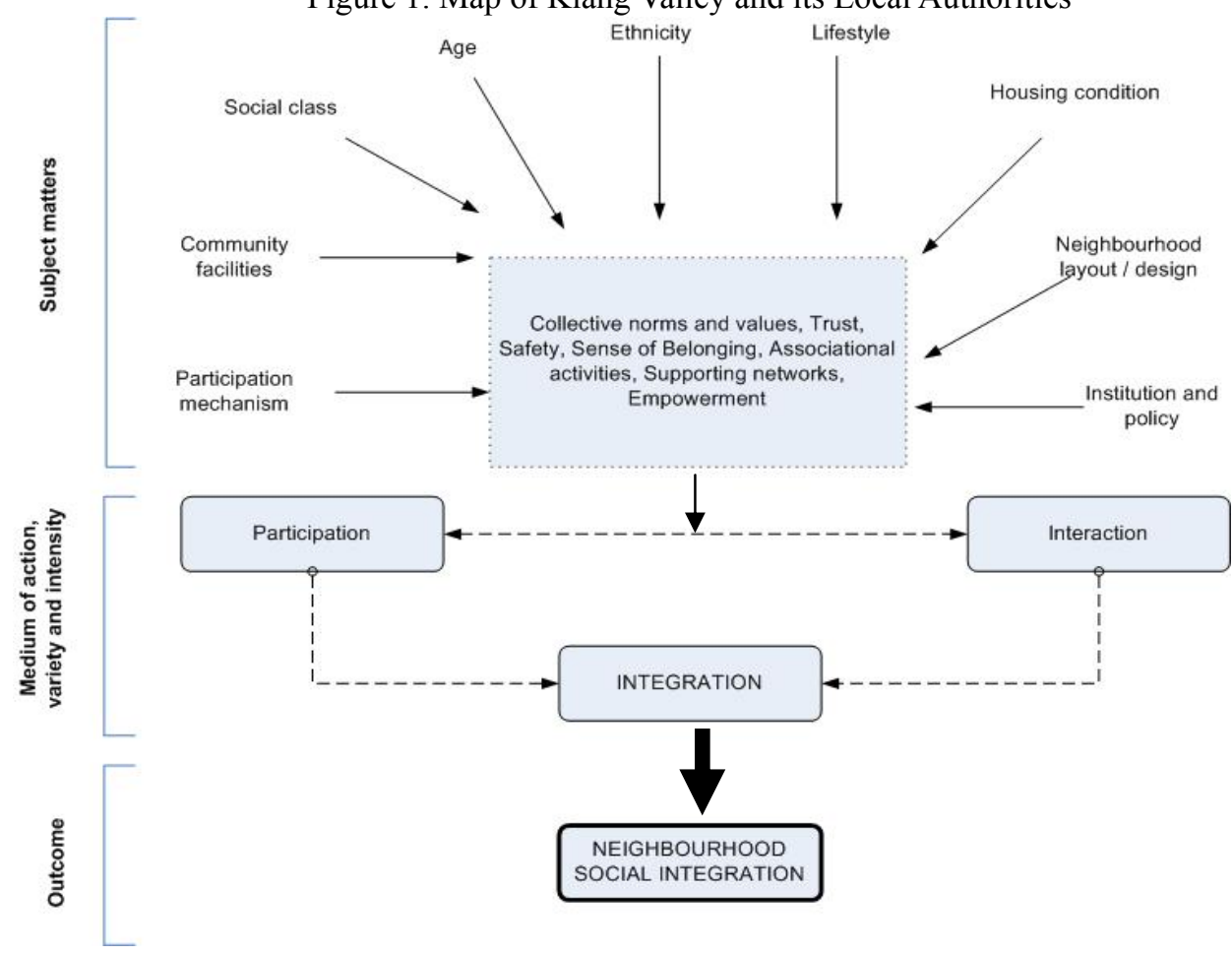

Figure 2. A conceptual model of neighbourhood social integration 